\title{
Uji Kesesuaian Pesawat $C T$ - Scan 64 Slice Merek Philips di Instalasi Radiologi Rumah Sakit Universitas Andalas Padang Menggunakan Detektor Unfors Raysafe $\mathrm{X}_{2}$
}

\author{
Khairunnisak $^{1, *}$, Dian Milvita ${ }^{1}$, Kri Yudi Pati Sandy ${ }^{2}$ \\ ${ }^{1}$ Jurusan Fisika Universitas Andalas \\ ${ }^{2}$ PTKMR BATAN Jakarta \\ e-mail :*khairunisa38@gmail.com
}

\begin{abstract}
ABSTRAK
Telah dilakukan uji kesesuaian pesawat CT-Scan 64 slice merek Philips menggunakan detektor unfors raysafe $X_{2}$ di Instalansi Radiologi Rumah Sakit Universitas Andalas. Jenis pengujian yang dilakukan diantaranya, uji akurasi tegangan, uji liniearitas keluaran radiasi, uji indeks dosis CT (CTDI), uji posisi meja pemeriksaan dan uji kesesuaian laser penanda. Hasil yang didapatkan yaitu akurasi tegangan memiliki rata-rata \% error sebesar 0,86\%; liniearitas keluaran radiasi memiliki CL (Coefisient of Linearity) sebesar 0,010; indeks dosis $C T$ (CTDI) dengan rata-rata $\mathrm{CTDI}_{100}$ sebesar 15,$0536 ; \Delta \mathrm{z}$ posisi meja pemeriksaan sebesar 0 ; uji laser penanda $\Delta_{\text {laser }} \leq$ tebal slice minimum yaitu $0,5 \mathrm{~mm}$. Pesawat CT-Scan 64 slice merek Philips dalam kondisi andal menurut Paraturan BAPETEN Nomor 9 Tahun 2011.

Kata kunci : pesawat CT-Scan, uji kesesuaian, unfors raysafe $x_{2}$
\end{abstract}

\begin{abstract}
The compliance test on the Philips 64 slice CT-Scan by using unfors raysafe $X_{2}$ detector at Radiology Unit Andalas University Hospital has been conducted. The testing type performed inclued voltage accuracy test, linearity of the output radiation test, CT dose index test (CTDI), examination table position and laser maker suitability test. The result show that voltage acuration have an average error of 0.86\%; linearity of radiation output have value of CL (Coefficient of Linearity) equal to 0.010; CT dose index (CTDI) have CTDI 100 average of 15.0536: $\Delta z$ of examination table position obtained is 0; laser marker uniformity Llaser $\leq$ minimum slice thickness of $0.5 \mathrm{~mm}$. CT-Scan 64 slice Philips brand in a reliable condition and according to the Head of BAPETEN regulation No. 9 year 2011.
\end{abstract}

Keywords: CT-Scan, conformance test, unfors raysafe $x_{2}$

\section{PENDAHULUAN}

Salah satu aplikasi sinar-X dalam bidang kesehatan adalah pemanfaatan CT-Scan untuk diagnosis penyakit. CT-Scan digunakan karena lebih canggih dalam mendiagnosis serta memonitor beragam kondisi kesehatan, hemat waktu dan kualitas gambar yang dihasilkan lebih jelas dibandingkan dengan pesawat sinar-X radiografi umum, sehingga hasil diagnosis penyakit pasien lebih akurat. Namun paparan radiasi sinar-X pada pemeriksaan CT-Scan juga memiliki efek negatif bagi manusia dan lingkungan jika digunakan dalam dosis radiasi yang berlebihan. Untuk menghindari penerimaan dosis radiasi yang berlebihan pada saat melakukan scanning maka pesawat $C T$-Scan tersebut perlu dilakukan uji kesesuaian.

Uji kesesuaian adalah uji untuk memastikan pesawat sinar-X dalam kondisi andal, baik untuk kegiatan radiologi diagnostik maupun intervensional dan memenuhi peraturan perundangundangan. Uji kesesuaian dilakukan agar tidak menimbulkan kerugian pada pasien, radiografer dan lingkungan dalam penerimaan dosis radiasi. Uji kesesuaian pesawat sinar-X untuk radiologi diagnostik dan intervensional diatur berdasarkan Peraturan Kepala BAPETEN Nomor 9 Tahun 2011 tentang uji kesesuaian pesawat sinar-X radiologi diagnostik dan intervensional.

Penelitian mengenai pengaruh diameter fantom dan tebal slice terhadap nilai CTDI pada pemeriksaan pesawat CT-Scan merek Philips brilliance 6 telah dilakukan oleh Aprilyanti dkk.(2013) di Instalasi Radiologi RSUP Dr.M.Djamil Padang. Penelitian ini menggunakan detektor pencil ion chamber pada unfors xi set untuk pengukuran dosis radiasi di dalam bagian fantom. Dari hasil pengukuran diperoleh nilai CTDI fantom lebih kecil dari nilai CTDI berdasarkan SK-BAPETEN No.01-P/Ka-BAPETEN/I-03 dan nilai CTDI pada fantom lebih besar dari nilai CTDI pada pasien, tetapi keduanya masih berada di bawah nilai batas dosis yang direkomendasikan oleh BAPETEN. 
Penelitian mengenai faktor fantom dan estimasi dosis efektif dari hasil pengukuran computed tomography dose index (CTDI) telah dilakukan oleh Manzil (2011) di Instalansi Radiologi Griya Puspa Rumah Sakit Persahabatan (RSP) Jakarta Timur. Penelitian ini menggunakan pesawat CT-Scan Siemens Somatom Sensation 64 dan dosimeter Unfors Xi dengan melakukan uji kualitas citra pesawat CT-Scan Siemens Somatom Sensation 64. Hasil penelitian menunjukkan bahwa pesawat CT-Scan Siemens Somatom Sensation 64 milik Instalansi Radiologi Griya Puspa Rumah Sakit Persahabatan (RSP) Jakarta Timur dalam keadaan baik.

Penelitian mengenai uji kesesuaian $C T$ number pada pesawat $C T$-Scan multi slice di unit Radiologi Rumah Sakit Islam Yogyakarta PDHI telah dilakukan oleh Mas'uul dan Sutanto (2014). Penelitian ini menggunakan pesawat CT-Scan dengan merk GE Healthcare jenis Hi Speed Dual CT Scanner dan menggunakan water phantom diameter $26,5 \mathrm{~cm}$ dan tebal $9 \mathrm{~cm}$. Hasil penelitian menunjukkan bahwa hasil bacaan CT number pada pesawat $C T$-Scan multi slice di Unit Radiologi Rumah Sakit Islam Yogyakarta PDHI masih memenuhi syarat yang direkomendasikan PERKA BAPETEN Nomor 9 Tahun 2011 tentang jaminan kualitas QA atau QC pesawat CT-Scan.

Penelitian mengenai uji kesesuaian pesawat CT-Scan merek Philips Briliance 6 telah dilakukan oleh Chirsnia dkk. (2013) di Instalasi Radiologi RSUP Dr. M. Djamil Padang. Penelitian ini menggunakan detektor Unfors Xi Set. Hasil penelitian menunjukkan bahwa pesawat $C T$-Scan tersebut dalam kondisi andal dengan perbaikan.

Pada penelitian ini dilakukan uji kesesuaian terhadap pesawat CT-Scan 64 slice merek Philips pada Instalasi Radiologi Rumah Sakit Universitas Andalas Padang. Uji kesesuaian ini sangat penting dilakukan, selain mematuhi peraturan yang telah diatur oleh pemerintah, pesawat CT-Scan milik rumah sakit tersebut masih baru dan adanya pemindahan alat dari lokasi satu ke lokasi lain dikhawatirkan mengalami pengurangan fungsi kerja alat sehingga perlu dilakukan uji kesesuaian untuk memastikan pesawat CT-Scan tersebut dalam kondisi layak digunakan. Pengujian pesawat CT-Scan mengacu pada Peraturan Kepala BAPETEN Nomor 9 Tahun 2011 tentang uji kesesuaian pesawat sinar-X radiologi diagnostik dan intervensional. Pengukuran yang dilakukan meliputi : akurasi tegangan, linieritas keluaran radiasi, indeks dosis CT (CTDI), posisi meja pemeriksaan, kesesuaian laser penanda dan kualitas citra, detektor yang digunakan pada penelitian ini adalah Unfors Raysafe $X_{2}$ set. Kelebihan detektor ini dibandingkan dengan detektor detektor lain yaitu sangat sensitif terhadap radiasi, mudah dipindahkan dan mudah digunakan.

\section{METODE}

Alat yang digunakan pada penelitian ini adalah pesawat CT-Scan 64 slice merek philips sebagai objek uji kesesuaian, detektor unfors-xi set yang terdiri dari detektor pencil ion chamber untuk mengukur dosis CTDI, detektor $\mathrm{kV}$ untuk mengukur tegangan pesawat CT-Scan dan unfors $\mathrm{kV}$ untuk menampilkan nilai yang terukur pada detektor, fantom PMMA (polymethylmethacrylate) sebagai pengganti pasien.

\subsection{Uji Kesesuaian Akurasi Tegangan}

Uji kesesuaian akurasi tegangan dilakukan melalui tahapan sebagai berikut : persiapan alat dan pengaturan parameter sesuai standar protokol uji, detektor $\mathrm{kV}$ diletakkan pada pusat gantryCT-Scan menggunakan laser penanda, tegangan divariasikan $80 \mathrm{kV}, 100 \mathrm{kV}, 120 \mathrm{kV}, 140$ $\mathrm{kV}$, dan error data dihitung menggunakan Persamaan (1)

$$
\text { error }=\left|\frac{k V_{p, s e t}-k V_{p, u k u r}}{k V_{p, \text { set }}}\right| 100 \%
$$

\subsection{Uji Kesesuaian Linieritas Keluaran Radiasi}

Uji kesesuaian linieritas keluaran radiasi dilakukan melalui tahapan berikut: detektor $\mathrm{kV}$ di posisikan pada pusat gantry CT-Scan menggunakan laser penanda, scanning dilakukan 
dengan tegangan $120 \mathrm{kVp}$ dan rentang (50-250) mAs, nilai dosis radiasi yang terbaca pada unfors display diplot pada grafik linier dengan fungsi arus waktu. Nilai lolos uji linieritas keluaran radiasi dinyatakan dengan Coefisient of Linearity, Coefisient of Linearity dihitung menggunakan Persamaan (2)

$$
C L=\left|\frac{(m G y / m A s)_{\max }-(m G y / m A s) \min }{(m G y / m A s)_{\text {max }}+(m G y / m A s)_{\text {min }}}\right|
$$

\subsection{Uji Kesesuaian Indeks Dosis CT (CTDI)}

Uji kesesuaian indeks dosis $C T$ (CTDI)melalui tahapan berikut: fantom PMMA diletakkan pada holder kepala pasien dan diletakkan di tengah-tengah gantry, pencil ion chamber diletakkan pada pusat fantom. Nilai indeks dosis dihitung menggunakan Persamaan (3) dan nilai lolos uji untuk indeks dosis $C T$ (CTDI) tidak boleh melebihi nilai CTDI baseline pabrikan.

$$
C T D I_{100}=\frac{k \times E \times L}{N \times T}
$$

\subsection{Uji Kesesuaian Posisi Meja Pemeriksaan}

Uji kesesuaian posisi meja pemeriksaan melalui tahapan sebagai berikut: meteran di tempatkan pada penyangga meja pemeriksaan dan diberi tanda pada meja tersebut, penanda pada meja pemeriksaan tersebut diatur ke posisi nol pada meteran dan dicatat bacaan pada konsol pesawat CT-Scan, meja pemeriksaan digerakkan melalui konsol pesawat CT-Scan dan dibandingkan jarak yang ditempuh oleh meja antara skala meteran dengan bacaan konsol pesawat CT-Scan.

\subsection{Uji Kesesuaian Laser Penanda}

Uji kesesuaian laser penanda melalui tahapan sebagai berikut : fantom CT-Scan di posisikan pada pusat gantry dan laser penanda pada CT-Scan dinyalakan, scanning dilakukan dan dilakukan pengamatan hasil citra melalui data DICOM yang dihitung menggunakan software philips DICOM viewer, nilai lolos uji laser penanda $\Delta_{\text {laser }} \leq$ tebal slice minimum.

\section{HASIL DAN DISKUSI}

Hasil uji kesesuaian dibandingkan dengan Peraturan Kepala BAPETEN Nomor 9 Tahun 2011. Berdasarkan Peraturan Kepala BAPETEN Nomor 9 Tahun 2011 Pasal 30 yang menyatakan 3 kondisi pesawat CT-Scan setelah dilakukan uji kesesuaian yaitu: kondisi pesawat CT-Scan dinyatakan andal apabila memenuhi nilai lolos uji dari seluruh parameter uji kesesuaian yang dilakukan, kondisi pesawat CT-Scan dinyatakan andal dalam perbaikan apabila sebagian memenuhi nilai lolos uji dari parameter uji kesesuaian tetapi tidak memenuhi nilai lolos uji pada parameter yang lainnya, kondisi pesawat $C T$-Scan dinyatakan tidak andal apabila tidak memenuhi nilai lolos uji dari seluruh parameter uji kesesuaian.

\subsection{Uji Kesesuaian Akurasi Tegangan}

Hasil pengujian akurasi tegangan pesawat $C T$-Scan diperoleh data yang ditunjukkan pada Tabel 1. Hasil pengujian menunjukkan nilai error \% pada masing-masing tegangan pesawat CT-Scan. Nilai tegangan yang terbaca pada alat ukur detektor $\mathrm{kV}$, tidak jauh berbeda dengan nilai tegangan yang diatur pada konsol pesawat CT-Scan. Pada kenyataannya keadaan ideal sangat sulit dicapai karena ketika pesawat CT-Scan melakukan scanning terjadi pengurangan efisiensi kerja. Faktor-faktor yang mempengaruhi efisiensi kerja pesawat $C T$-Scan salah satunya adalah kestabilan listrik yang digunakan pada saat pengambilan data. Hal ini menyebabkan pesawat CT-Scan bekerja tidak optimal. Nilai lolos uji yang masih 
diperkenankan oleh Peraturan Kepala BAPETEN Nomor 9 Tahun 2011 untuk nilai error tegangan adalah $\leq 6 \%$. Berdasarkan data yang diperoleh bahwa seluruh tegangan pesawat $C T$ Scan berada pada nilai lolos uji yang telah ditetapkan oleh Peraturan Kepala BAPETEN Nomor 9 Tahun 2011, yaitu e $\leq 6 \%$.

Tabel 1 Data hasil uji akurasi tegangan

\begin{tabular}{cccc}
\hline No & $\mathbf{k V p _ { \text { setting } }}(\mathbf{k V )}$ & $\mathbf{k V} \mathbf{p}_{\text {terukur }}(\mathbf{k V})$ & Error $\mathbf{\%})$ \\
\hline 1 & 80 & 79,80 & $0,25 \%$ \\
2 & 100 & 100,40 & $0,4 \%$ \\
3 & 120 & 118,80 & $1,00 \%$ \\
4 & 140 & 137,50 & $1,79 \%$ \\
\hline \multicolumn{3}{c}{ Nilai lolos uji } & Error $e \leq 6 \%$ \\
\hline
\end{tabular}

\subsection{Uji Kesesuaian Linieritas Keluaran Radiasi}

Pada penelitian uji linearitas keluaran radiasi pesawat CT-Scan diperoleh data yang ditunjukkan pada Tabel 2. Pada hasil pengujian terdapat variasi arus yang dialirkan pada pesawat CT-Scan yaitu $50 \mathrm{mAs}, 100 \mathrm{mAs}, 150 \mathrm{mAs}, 200 \mathrm{mAs}$ dan $250 \mathrm{mAs}$, sedangkan untuk tegangan diatur tetap pada $120 \mathrm{kV}$ dalam waktu 1 sekon. Hal ini dilakukan untuk mengamati kelinieran keluaran radiasi pada saat arus yang berubah-ubah. Nilai lolos uji yang masih diperkenakan oleh Peraturan Kepala BAPETEN Nomor 9 Tahun 2011 untuk nilai $C L$ (Coefisient of Linearity) adalah $\leq 0,1$. Hasil pengujian menunjukkan bahwa nilai CL (Coefisient of Linearity) yang diperoleh pada saat penelitian adalah 0,010. Berdasarkan hasil uji tersebut data yang diperoleh telah memenuhi nilai lolos uji yang telah ditetapkan oleh Peraturan Kepala BAPETEN Nomor 9 Tahun 2011.

Tabel 2 Data hasil uji linearitas keluaran radiasi

\begin{tabular}{ccccc}
\hline No & $\begin{array}{c}\text { Dosis radiasi } \\
(\mathbf{m G y})\end{array}$ & $\mathbf{m A S}_{\text {set }}(\mathbf{m A s})$ & $(\mathbf{m G y} / \mathbf{m A s})$ & $\boldsymbol{C L}$ \\
\hline 1 & 1,003 & 50 & 0,02006 & \\
2 & 2,002 & 100 & 0,02002 & \\
3 & 3,005 & 150 & 0,02003 & 0,010 \\
4 & 4,015 & 200 & 0,02007 & \\
5 & 4,979 & 250 & 0,01991 & $C L \leq 0,1$ \\
\hline \multicolumn{5}{c}{ Nilai lolos uji }
\end{tabular}

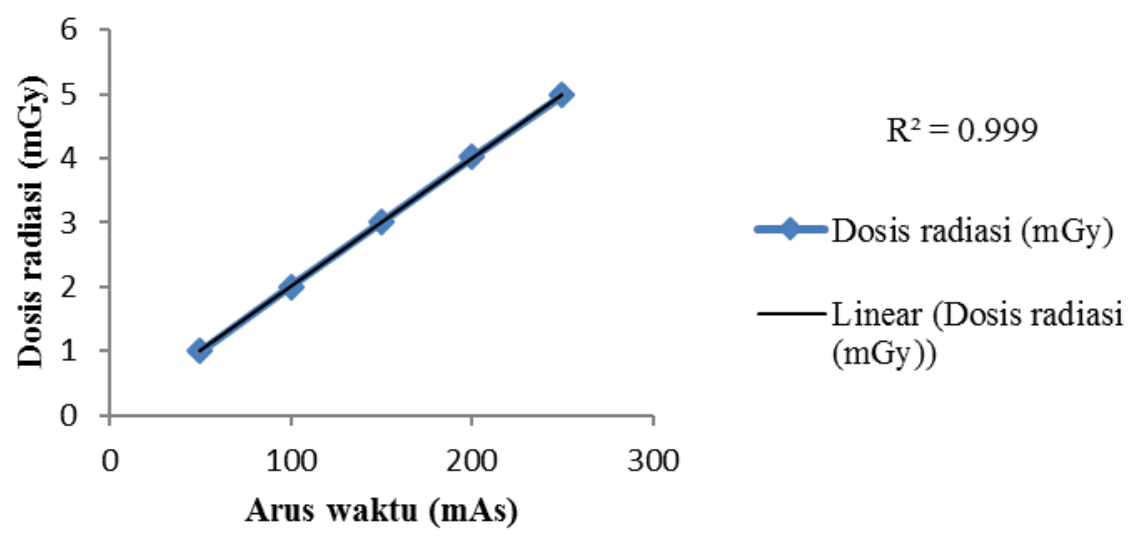

Gambar 1 Linieritas keluaran radiasi

Nilai linieritas keluaran radiasi pesawat $C T$-Scan dinyatakan dengan nilai $\mathrm{R}^{2}$ pada grafik Gambar 1. Nilai $\mathrm{R}^{2}$ menyatakan koefisien korelasi yang terbentuk dari linieritas hubungan dosis radiasi dan arus waktu pada pesawat CT-Scan. Nilai $\mathrm{R}^{2}$ yang diperoleh dibandingkan dengan nilai lolos uji Coefisient of Linearity yang diperkenankan oleh Peraturan Kepala BAPETEN Nomor 9 Tahun 2011. Untuk uji linieritas keluaran radiasi diketahui bahwa 
nilai yang diperkenankan yaitu $\mathrm{CL} \leq 0,1$ sedangkan nilai $\mathrm{R}^{2}$ yang diperoleh yaitu 0,999 . Berdasarkan hasil uji tersebut diketahui bahwa nilai dosis radiasi linear terhadap arus yang diberikan pada pesawat CT-Scan, sehingga data yang diperoleh bahwa pesawat CT-Scan tersebut berada pada nilai lolos uji yang telah ditetapkan oleh Peraturan Kepala BAPETEN Nomor 9 Tahun 2011, yaitu $\mathrm{CL} \leq 0,1$.

\subsection{Uji Kesesuaian Indeks Dosis CT (CTDI)}

Uji kesesuaian dosis radiasi pasien menggunakan fantom diameter $16 \mathrm{~cm}$ mewakili organ kepala orang dewasa diperoleh data seperti ditunjukkan pada Tabel 3. Hasil pengujian menunjukkan nilai $C T D I_{100}$ (mGy/100mAs) menggunakan fantom diameter $16 \mathrm{~cm}$ yang mewakili organ kepala orang dewasa. Nilai lolos uji berdasarkan Peraturan Kepala BAPETEN Nomor 9 Tahun 2011 untuk CTDI100 (mGy/100mAs) tidak boleh melebihi CTDI $I_{100}$ (mGy/100mAs) baseline pabrikan, yaitu 15,886. Berdasarkan data yang diperoleh pada penelitian bahwa nilai $C T D I_{100}(\mathrm{mGy} / 100 \mathrm{mAs})$ pada pengukuran sesuai dengan nilai CTDI100 (mGy/100mAs) baseline pabrikan, sehingga data yang diperoleh pada penelitian telah memenuhi nilai lolos uji yang ditetapkan oleh Peraturan Kepala BAPETEN Nomor 9 Tahun 2011, yaitu nilai lolos uji $C T D I_{100}$ (mGy/100mAs) baseline pabrikan.

Tabel 3 Data hasil uji kesesuaian dosis radiasi pasien menggunakan fantom diameter $16 \mathrm{~cm}$

\begin{tabular}{|c|c|c|c|c|}
\hline Posisi detektor & $\begin{array}{c}\text { Dosis } \\
(\mathrm{mGy})\end{array}$ & $C T D I_{100}(\mathrm{mGy})$ & $\begin{array}{c}C T D I_{100} \\
(\mathrm{mGy} / \mathrm{mAs})\end{array}$ & $\begin{array}{c}C T D I_{100} \\
(\mathrm{mGy} / 100 \mathrm{mAs}) \\
\end{array}$ \\
\hline Tengah & $\begin{array}{l}4,964 \\
5,008\end{array}$ & 49,860 & 0,142 & 14,246 \\
\hline Tepi 1 (jam 12) & $\begin{array}{l}5,668 \\
5,492 \\
\end{array}$ & 55,800 & 0,159 & 15,943 \\
\hline Tepi 2 (jam 3) & $\begin{array}{c}5,18 \\
5,192\end{array}$ & 51,860 & 0,148 & 14,817 \\
\hline Tepi 3 (jam 6) & $\begin{array}{c}5,1 \\
5,138\end{array}$ & 51,190 & 0,146 & 14,626 \\
\hline Tepi 4 (jam 9) & $\begin{array}{l}5,574 \\
5,371 \\
\end{array}$ & 54,725 & 0,156 & 15,636 \\
\hline \multicolumn{4}{|c|}{ Nilai lolos uji $C T D I_{100}(\mathrm{mGy} / 100 \mathrm{mAs})$} & 15,886 \\
\hline
\end{tabular}

\subsection{Uji Kesesuaian Posisi Meja Pemeriksaan}

Setelah dilakukan pengujan terhadap meja pemeriksaan pesawat CT-Scan, data yang diperoleh ditunjukkan pada Tabel 4. Penelitian uji kesesuaian posisi meja pemeriksaan pesawat CT-Scan bertujuan untuk melihat kecocokan pergeseran posisi meja pemeriksaan antara pengaturan melalui konsol pesawat CT-Scan dengan pergeseran sebenarnya. Pada saat penelitian uji kesesuaian posisi meja pemeriksaan dilakukan pengujian tanpa menggunakan massa dan diberi massa yang ditempatkan pada meja tersebut sebesar $70 \mathrm{~kg}$. Idealnya besar massa tidak mempengaruhi keadaan meja, karena meja akan tetap pada posisinya saat diberi massa ataupun tidak. Hasil pengujian menunjukkan bahwa selisih antara posisi meja ketika digerakkan melalui konsol dengan yang terukur menggunakan meteran adalah nol untuk tiga kali pengulangan, artinya tidak ada pergeseran yang berlebih atupun berkurang.

Tabel 4 Data hasil uji kesesuaian posisi meja pemeriksaan tanpa menggunakan massa dan menggunakan massa sebesar $70 \mathrm{~kg}$

\begin{tabular}{cclccc}
\hline No. & $\begin{array}{c}\text { Massa } \\
(\mathbf{k g})\end{array}$ & Pergerakan & $\begin{array}{c}\text { Terukur pada } \\
\text { mistar }(\mathbf{m m})\end{array}$ & $\begin{array}{c}\text { Terukur di indikator } \\
\text { gantry }(\mathbf{m m})\end{array}$ & $\begin{array}{c}\text { Deviasi } \\
(\mathbf{\Delta z})\end{array}$ \\
\hline 1 & 0 & Maju/mundur & 10 & 10 & 0 \\
\hline 2 & 70 & Maju/mundur & 50 & 50 & 0 \\
\hline 3 & 70 & Maju/mundur & 100 & 100 & 0 \\
\hline
\end{tabular}




\subsection{Uji Kesesuaian Laser Penanda}

Berdasarkan penelitian uji laser penanda pesawat CT-Scan diperoleh data yang ditunjukkan pada Tabel 5. Posisi pengambilan sampel ditunjukkan pada Gambar 2. Penelitian mengenai uji laser penanda pesawat $C T$-Scan bertujuan untuk menandai posisi organ yang akan diberi pemeriksaan CT-Scan. Berdasarkan PERKA BAPETEN Nomor 9 Tahun 2011 nilai lolos uji untuk laser penanda pesawat $C T$-Scan $\Delta_{\text {Laser }} \leq$ tebal slice minimum yaitu $0,5 \mathrm{~mm}$. Nilai pergeseran laser yang diperoleh pada penelitian ini yaitu $\leq 0,5 \mathrm{~mm}$. Maka nilai yang diperoleh pada saat penelitian telah memenuhi PERKA BAPETEN Nomor 9 Tahun 2011.

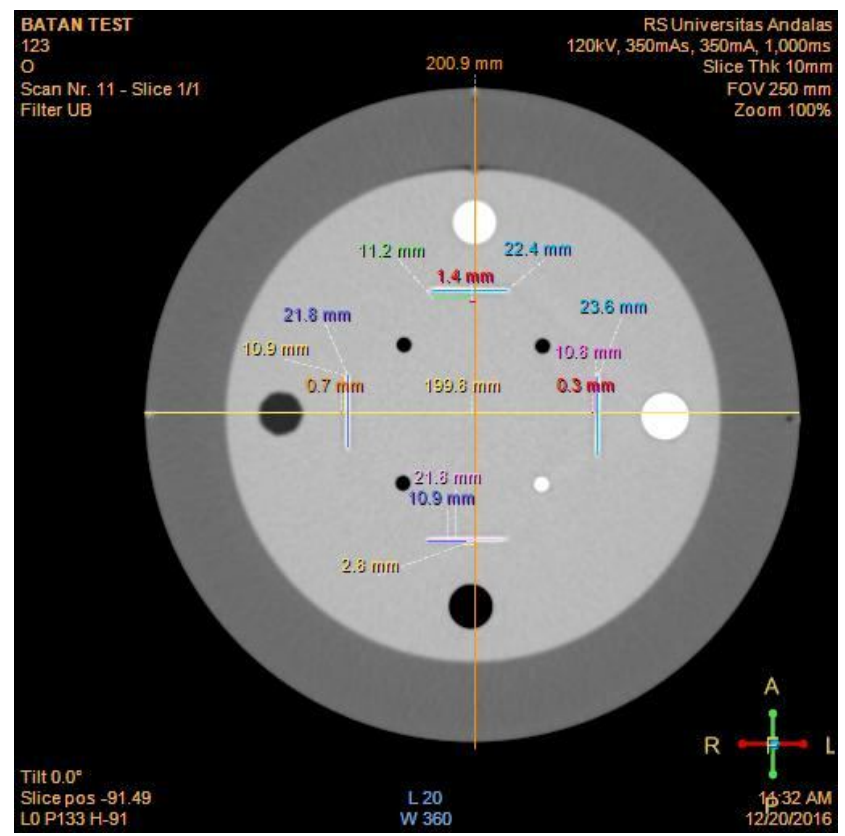

Gambar 2. Pengukuran uji laser penanda

Tabel 5 Data hasil uji laser penanda

\begin{tabular}{cc}
\hline Posisi & $\begin{array}{c}\text { Panjang penyimpangan citra } \\
{\left[\boldsymbol{\Delta}_{\text {Laser }}(\mathbf{m m})\right]}\end{array}$ \\
\hline Horizontal & 0,1 \\
Vertikal & 0,5 \\
\hline Nilai lolos uji $\Delta_{\text {Laser }} \leq$ tebal slice minimum & $0,5 \mathrm{~mm}$ \\
\hline
\end{tabular}

\section{KESIMPULAN}

Berdasarkan penelitian uji kesesuaian pesawat CT-Scan merek Philips dengan enam parameter uji berdasarkan Peraturan Kepala BAPETEN Nomor 9 Tahun 2011, diperoleh beberapa kesimpulan, yaitu pesawat CT-Scan merek Philips milik Rumah Sakit Universitas Andalas Padang yang menjadi objek pada penelitian secara umum berada dalam kondisi baik. Hasil yang didapatkan berada di bawah nilai lolos uji yang diperbolehkan oleh Peraturan Kepala BAPETEN Nomor 9 Tahun 2011, semakin besar arus yang digunakan maka semakin besar nilai dosis radiasi yang diterima, begitu juga sebaliknya., dan nilai CTDI yang diterima fantom pada arah jam 12 lebih besar dari pada arah yang lain. Hal ini disebabkan pada saat scanning dimulai pergerakkan gantry diawali dari jarum jam12 sehingga radiasi yang dipancarkan terlebih dahulu diterima pada posisi jam 12. Selain itu pergerakkan gantry juga diakhiri pada jam 12 sehingga dosis yang diterima fantom dua kali lebih banyak dari pada arah yang lain. 


\section{DAFTAR PUSTAKA}

Aprilyanti, D, D., Milvita, D., Prasetio, H., dan Yuliati, H., 2013, Pengaruh diameter phantom dan tebal slice terhadap nilai CTDI pada pemeriksaan CT-Scan, Jurnal Fisika Unand (JFU), Vol.2, No.2, Jur. Fisika Unand, Hal 81-87.

BAPETEN, 2011., Peraturan Kepala Badan Pengawas Tenaga Nuklir Nomor 9 Tahun 2011 Tentang Uji Kesesuaian Pesawat Sinar-X Radiologi Diagnostik Dan Intervensional.

Chirsnia, I., Milvita, D., Prasetio, H., dan Yuliati, H., 2013, Uji Kesesuaian Pesawat CT-Scan Merek Philips Briliance 6 dengan Peraturan Kepala BAPETEN Nomor 9 Tahun 2011, Jurnal Fisika Unand (JFU), Vol.2, No.2, Jur. Fisika Unand, Hal 120-127.

Manzil, E, 2011, Estimasi Dosis Efektif dari Hasil Pengukuran Computed Tomography Dose Index (CTDI), skripsi, Fakultas Matematika dan Ilmu Pengetahuan Alam, Universitas Indonesia.

Mas'uul, A,R., Sutanto, H., 2014, Uji Kesesuaian CT Number Pada Pesawat CT-Scan Multi Slice di Unit Radiologi Rumah Sakit Islam Yogyakarta PDHI, Youngster Physics Journal, Vol.3, No.4, Jur.Fisika Universitas Diponegoro, Hal 335-340. 